уки и образования. - 2008. - № 4. - С. 121-123.

12. Leamar E.E. (1984). Souses of International Comparative Advantage: Theory and Evidence, Cambridge, MIT Press: P. 353.

13. Soulie D. (1989). Filieres de Production et Integration Vertical. Annales des Mines, Janvier: P. 21-28.

14. Tolenado J.A. (1978). Propis des Filieres Industrielles Revue d' Economie Industrielle, Vol. 6, No 4: P. 149-158.

Камышова Галина Николаевна, канд. физ.-мат. наук, доцент, зав. кафедрой «Математика и математическое моделирование», Саратовский государственный аграрный университет имени Н.И. Вавилова. Россия.
Терехова Надежда Николаевна, канд. техн. наук, доцент кафедры «Математика и математическое моделирование», Саратовский государственный аграрный университет имени Н.И. Вавилова. Россия.

410012, г.Саратов, Театральная пл., 1.

Тел.: +79033296105; e-mail: gkamichova@mail.ru.

Терехов Павел Олегович, студент, Саратовский нацииональный исследовательский государственный университет имени Н.Г. Чернышевского. Россия.

410013, г. Саратов, ул. Астраханская, 89.

Тел.:(8452) 21-36-41.

ключевые слова: изифровая экономика; кластерный анализ; экономико-математическое моделирование; геоинформационные технологии; зерновой комплекс.

\title{
DIGITAL MODEL EVALUATION OF THE REGIONAL GRAIN SECTOR BASED ON INTEGRATED CLUSTER ANALYSIS
}

Kamyshova Galina Nickolaevna, Candidate of PhysicalMathematical Sciences, Associate Professor, Head of the chair "Mathematics and Mathematical Models", Saratov State Agrarian University named after N.I. Vavilov. Russia.

Terehova Nadezhda Nikolaevna, Candidate of Technical Sciences, Associate Professor of the chair "Mathematics and Mathematical Models", Saratov State Agrarian University named after N.I. Vavilov. Russia.

Terehov Pavel Olegovich, Student, Saratov State University named after N.G. Chernysheskiy. Russia.
Keywords: digital economy; cluster analysis; economic and mathematical modeling; geoinformation technologies; grain complex.

The article considers results of the analysis of grain production and agro-food market of grain crops. Digital visualized models of analysis and improvement of the grain complex of the region on the basis of integrated cluster analysis are proposed. The application of the digital economy, namely, the introduction of new information technologies, modern mathematical modeling tools and transfer of innovative solutions will further improve the efficiency and development of the potential of domestic agriculture.

удк 338

\section{ОСНОВНЫЕ НАПРАВЛЕНИЯ РАЗВИТИЯ РЕГИОНАЛЬНОГО МОЛОЧНО-ПРОДУКТОВОГО ПОДКОМПЛЕКСА}

\author{
ЛИХОВЦОВА Елена Александровна, Саратовский государственный аграрный университет \\ имени Н.И. Вавилова
}

ЕВСЮКОВА Людмила Юрьевна, Саратовский государственный аграрный университет имени Н.И. Вавилова

ЮРКОВА Марина Сергеевна, Поволжский научно-исследовательский институт экономики и организации АПК

\section{СЕРДОБИНЦЕВ Дмитрий Валерьевич, Поволжский научно-исследовательский институт} экономики и организации АПК

Проанализированы тендениии развития молочно-продуктового подкомплекса РФ и опыт кластерного развития в развитьх странах. Обоснована возможность создания кластера в Саратовской области, который исключит дублирование производственно-сбытовъх и маркетинговъх функций субъектов рынка молока, а также сократит совокупные издержки в среднем более чем на $4 \%$, что, по мнению авторов, приведет к повышению эффективности производства и появлению стимулов для развития инфраструктуры и сельских территорий.

Введение. Российский молочно-продуктовый подкомплекс характеризуется низкой социальноэкономической эффективностью, слаборазвитой сбытовой логистикой, противоречиями интересов субъектов рыночных отношений, несовершенством системы ценообразования, слабым развитием кооперационных и интеграционных связей, недостаточной интенсивностью инновационных и инвестиционных процессов. Рост агропроизводства в стране обеспечивается, в основном, за счет развития свиноводства и птицеводства.

В молочном скотоводстве большинства регионов РФ наблюдается системный кризис. При этом среди основных внешних факторов кризисного влияния на отрасль следует отметить недостаточный уровень господдержки, несовершенный механизм ее распределения, устранение государства от процессов ценообразования, монополизм торговых сетей, слабое развитие кооперации и интеграции. К внутренним факторам, в первую очередь, следует отнести низкую продуктивность животных и слабую генетическую базу, отсутствие современных научно обоснованных систем кормопроизводства, существующий пониженный уровень производительности труда, отсутствие эффективного финансового менеджмента и др.

Всё это является следствием разобщенности субъектов аграрного рынка в РФ и отсутствия единой политики ценообразования на всех уровнях произ- 
водства и распространения готовой агропродукции. Для выхода из сложившейся ситуации необходимо создавать территориальные структуры добровольного объединения производителей с переработчиками и инфраструктурой, торговыми сетями, учебными и научно-исследовательскими учреждениями, государственными структурами, например, в виде агропромышленных кластеров. В рамках таких структур будут развиваться межотраслевые отношения, система ценообразования, инфраструктура, кормовая и сырьевая базы, агрологистика, технологии, инвестиции, деятельность совместных предприятий, специализированные сельскохозяйственные рынки, инновации, повысится конкурентоспособность.

Цель исследования - определение современных тенденций и проблем функционирования регионального молочно-продуктового подкомплекса и обоснование перспектив его дальнейшего развития в Саратовской области.

Методика исследований. Системный подход и применение основных экономико-статистических методов: сравнения, факторного анализа, моделирования и прогнозирования позволили авторам проанализировать современное состояние и динамику функционирования молочно-продуктового подкомплекса РФ и Саратовской области, выделить основные тенденции его дальнейшего развития, факторы влияния на процесс ценообразования в отраслях молочного скотоводства и молокоперерабатывающей промышленности. При этом была проведена оценка системы сбыта и разработаны основные предложения по совершенствованию товародвижения и ценообразования в отраслях подкомплекса с учетом функционирования молочнопродуктового кластера.

Результаты исследований. Современная ситуация на рынке молока в развитых странах характеризуется дисбалансом между производством сырого молока и возможностями переработки. В результате выделяются основные тенденции развития отраслей молочнопродуктового подкомплекса в западных странах [4, 13-16]: поиск новых рынков сбыта молока и молочной продукции с преобладанием восточного направления (Ближний Восток, Саудовская Аравия); сокращение выплат производителям молока и потеря доходности; увеличение производства новых видов молочной продукции с максимальной ресурсной емкостью и развитие эксклюзивных экологически чистых производств; увеличение потребления молока и молочных продуктов, в том числе на корм животным; увеличение производства молока по программам обеспечения малоимущих семей; совершенствова- ние внедрения инновационной активности и новых моделей развития и управления на предприятиях; развитие информационного обеспечения, государственного надзора, моделирования в различных условиях, междисциплинарных методов исследования и диагностики.

В молочно-продуктовом подкомплексе АПК России наблюдается противоположная ситуация: дефицит производства сырого молока, высокая зависимость от импорта, низкая инновационная и инвестиционная активность, увеличениедоли фальсифицированной продукции, техническое и технологическое отставание, слабый научный подход к развитию молочного и мясного скотоводства $[1,2,5,6,12]$.

По официальным данным производство молока в 2000-2016 гг. в РФ снизилось почти на 5 \% и составило 30,7 млн т на конец 2016 г. [3]. По валовому производству молока Россия занимает по состоянию на начало 2017 г. 9-ю позицию в мире. Всего в мире в 2016 г. произведено 781 млн т молока, при этом наибольший прирост пришелся на Индию - более 10 \% и Пакистан - 3,8 \%. На долю 10 крупнейших стран производителей приходится 62,8 \% всего объема производства молока в мире, темпы роста достигают в среднем $2 \%$ за год [8].

Лидерами по объему потребления являются страны ЕС, Индия, США, Россия занимает пятое место с долей $5 \%$. В развитых странах уровень потребления молока составляет около 360-365 кг на душу населения, что в 3-4 раза больше, чем в развивающихся странах. Уровень потребления молока и молочных продуктов в России за 2016 г. опустился до 236 кг, что ниже рекомендованных Минздравом России норм почти на $19 \%$ [8].

В табл. 1, 2 приведена динамика производства и потребления молока в РФ по основным федеральным округам за 2012-2016 гг.

Как видно из данных табл. 1, лидером в производстве коровьего молока в РФ является Приволжский федеральный округ, где за 2016 г. произведено 9,41 млн т молока, или чуть более 30 \% от общего объема производства. Второе место по объему производства молока в РФ занимают 2 округа - Центральный и Сибирский. При этом за анализируемый период объемы производства молока в большинстве округов сократились.

Данные табл. 2 показывают сокращение среднего уровня потребления молока и молочных продуктов на душу населения в РФ за 2012-2016 гг., которое упало до 236 кг, или на 13 кг. По всем федеральным округам также наблюдается сокращение потребления за исключением Северо-Кавказского округа и Крыма,

Таблица 1

Производство молока в РФ по основным федеральным округам, млн т [3]

\begin{tabular}{|c|c|c|c|c|c|c|}
\hline Федеральный округ & 2012 г. & 2013 г. & 2014 г. & 2015 г. & 2016 г. & $\begin{array}{l}\text { Отклонение } 2016 \text { г. } \\
\text { от } 2012 \text { г., +/- }\end{array}$ \\
\hline Центральный & 5,78 & 5,49 & 5,39 & 5,4 & 5,43 & $-0,35$ \\
\hline Северо-Западный & 1,77 & 1,68 & 1,71 & 1,77 & 1,82 & 0,05 \\
\hline Южный & 3,37 & 3,3 & 3,28 & 3,3 & 3,57 & 0,20 \\
\hline Северо-Кавказский & 2,64 & 2,67 & 2,72 & 2,75 & 2,79 & 0,15 \\
\hline Приволжский & 9,95 & 9,48 & 9,47 & 9,49 & 9,41 & $-0,54$ \\
\hline Уральский & 2,08 & 2,02 & 1,99 & 1,9 & 1,89 & $-0,19$ \\
\hline Сибирский & 5,58 & 5,3 & 5,38 & 5,38 & 5,27 & $-0,31$ \\
\hline Дальневосточный & 0,57 & 0,56 & 0,53 & 0,54 & 0,53 & $-0,04$ \\
\hline Крым & - & - & 0,29 & 0,25 & 0,24 & 0,24 \\
\hline Всего & 31,75 & 30,53 & 30,79 & 30,79 & 30,75 & $-1,00$ \\
\hline
\end{tabular}




\section{Потребление молока и молочных продуктов в расчете на душу населения в РФ} по основным федеральным округам, кг [3]

\begin{tabular}{|c|c|c|c|c|c|c|}
\hline Федеральный округ & 2012 г. & 2013 г. & 2014 г. & 2015 г. & 2016 г. & $\begin{array}{c}\text { Отклонение } 2016 \text { г. от } \\
2012 \text { г., }+ \text { - }\end{array}$ \\
\hline Центральный & 233 & 233 & 226 & 221 & 217 & -16 \\
\hline Северо-Западный & 276 & 277 & 276 & 268 & 268 & -8 \\
\hline Южный & 237 & 236 & 234 & 229 & 218 & -19 \\
\hline Северо-Кавказский & 237 & 237 & 241 & 241 & 242 & 5 \\
\hline Приволжский & 283 & 281 & 277 & 272 & 270 & -13 \\
\hline Уральский & 211 & 213 & 211 & 205 & 201 & -10 \\
\hline Сибирский & 264 & 262 & 259 & 255 & 251 & -13 \\
\hline Дальневосточный & 192 & 196 & 193 & 191 & 191 & $\frac{1}{-1}$ \\
\hline Крым & - & - & 183 & 163 & 165 & 165 \\
\hline В среднем по РФ & 249 & 248 & 244 & 239 & 236 & -13 \\
\hline
\end{tabular}

что связано с увеличением там производства молока. Лидером по потреблению молока и молочных продуктов среди округов РФ является Приволжский федеральный округ, потребление здесь в 2016 г. составило 270 кг на душу населения, что выше среднего показателя по стране.

Саратовская область входит в состав Приволжского федерального округа и является одним из основных производителей и поставщиков молока-сырья на рынок Поволжья, уступая Республике Татарстан [3].

В результате проведенного исследования сырьевой зоны молочно-продуктового подкомплекса Саратовской области, выявлены основные факторы, влияющие на развитие молочного скотоводства (табл. 3). Эти факторы разделены на внутрифирменные (с позиции отдельного производителя) и внешние, оказывающие влияние с позиций внутренней политики и различных государственных, финансово-кредитных, общественных и иных институтов.

Проблема ценообразования является одной из центральных при определении направления устойчивого развития молочно-продуктового подкомплекса в РФ, так как затрагивает фундаментальные основы товарного производства. Ценовая ситуация на рынке молока зависит от существующих тенденций в отрасли [9] и обусловливается фундаментальными и конъюнктурными факторами (табл. 4).

Проведенное исследование рынка молока и молочных продуктов в РФ за 2012-2016 гг. показало высокую волатильность цен на сырое молоко в зависимости от времени года. На рынке существует проблема переизбытка молока-сырья в летние месяцы и недостаток в зимний период, поэтому повышение цен в зимние месяцы является традиционным. Повышение цен на молоко-сырье за последние годы неразрывно связано с процессами инфляции и девальвацией рубля, повышением затрат на обслуживание импортного оборудования и недоступностью кредитных ресурсов для большинства мелких и средних производителей. Например, в 2013-2016 гг. на рынке молока наблюдался небывалый рост цен на сырое молоко - на 64,4 \%, однако цены промышленных производителей молочных продуктов выросли на 47,7 \%, розничные цены - на 51,8 \% [10]. При этом среднедушевые денежные доходы населения в РФ за последние 5 лет увеличились в среднем только на 19 \%, но существуют категории населения с низкими, средними доходами и доходами ниже прожиточного минимума, численность которых неуклонно растет. Так, в 2013-2017 гг. численность этих категориий граждан увеличилась на 24,5 \%, достигнув 19,8 млн человек в 2017 г. [7].

В результате всего вышеизложенного и для решения задач развития молочно-продуктового подкомплекса в регионах необходимо создание агропромышленных кластеров. При этом ядром кластера и регулятором, в первую очередь, производственно-сбытовых отношений и ценообразования будут являться заводы по переработке молока. Это будет обусловлено, прежде всего, сложившимся размещением производства в регионах еще в советские времена, а так жетем, что заводы по переработке являются конечным элементом в производственно-технологической цепи и могут создавать собственные торговые сети, развивать инфраструктуру, привлекать ресурсы, инвестировать в развитие сырьевых зон и социальную сферу [9].

Также большинство средних и малых товаропроизводителей в регионах не имеют прямых контактов с потребителем, между ними находятся

Таблица 3

Факторы, влияющие на развитие молочного скотоводства РФ

\begin{tabular}{|l|l|}
\hline \multicolumn{1}{|c|}{ Внутрифирменные факторы влияния } & \multicolumn{1}{|c|}{ Внешние факторы влияния } \\
\hline $\begin{array}{l}\text { 1. Развитие аграрной логистики на предприятии } \\
\text { р. Внедрение и освоение инноваций, научный подход к принятию }\end{array}$ & 1. Аграрная и налоговая политика \\
\hline 3. Повышение уровня механизации животноводства & Финансово-кредитная и ценовая политика \\
\hline $\begin{array}{l}\text { 4. Совершенствование генетики животных, развитие кормопроизводс- } \\
\text { тва и земельных отношений }\end{array}$ & $\begin{array}{l}\text { 4. Совершенствование программ по развитию животноводства и } \\
\text { смежых отраслей молочно-продуктового подкомплекса на феде- } \\
\text { ральном, региональном и муниципальном уровнях }\end{array}$ \\
\hline $\begin{array}{l}\text { 5. Повышение квалификации персонала, обмен опытом с передовыми } \\
\text { хозяйствами }\end{array}$ & 5. Стимулирование процессов кооперации, интеграции и кластеризации \\
\hline 6. Совершенствование договорной деятельности и ценовой политики & б. Развитиепроизводственной, социальной и рыночной инфраструктуры \\
\hline 7. Тип воспроизводственного процесса & $\begin{array}{l}\text { 7. Развитие агротуризма, в том числе, экотуризма и этнотуризма в } \\
\text { сельских территориях }\end{array}$ \\
\hline $\begin{array}{l}\text { 8. Индивидуальный подход к развитию предприятия, к персоналу, } \\
\text { стратегический менеджмент }\end{array}$ & $\begin{array}{l}\text { 8. Стимулирование программ инновационно-инвестиционного } \\
\text { развития в отраслях подкомплекса }\end{array}$ \\
\hline 9. Продуктивность животных & $\begin{array}{l}\text { 9. Государственное регулирование рынка молока и молочных } \\
\text { продуктов посредством интервенций и установления ценового } \\
\text { коридора }\end{array}$ \\
\hline 10. Совершенствование управления и организации на предприятии & 10. Уровень монополизации рынка сырья и готовой продукции \\
\hline
\end{tabular}


Факторы ценообразования на рынке молока-сырья

\begin{tabular}{|l|l|}
\hline \multicolumn{1}{|c|}{ Со стороны производителей молока-сырья } & \multicolumn{1}{|c|}{ Со стороны молочных заводов } \\
\hline 1. Себестоимость производства & 1. Методика ценообразования \\
\hline 2. Объем субсидий и государственной поддержки & 2. Ассортимент продукции и средние издержки производства \\
\hline 3. Планируемая прибыль & 3. Конъюнктура рынка, ожидания продавцов \\
\hline 4. Качество и уровень первичной обработки продукции & 4. Уровень конкуренции на рынке \\
\hline 5. Ожидаемый и фактический спрос & $\begin{array}{l}\text { 5. Уровень постоянных и переменных издержек производства } \\
\text { молочной продукции }\end{array}$ \\
\hline 6. Конъюнктура рынка & 6. Планируемая прибыль \\
\hline 7. Договорные обязательства & $\begin{array}{l}\text { 7. Качество сырья (закупаемого молока), корректировка и } \\
\text { дифференциция конечной цены в рамках системы надбавок }\end{array}$ \\
\hline 8. Наличие альтернативных вариантов сбыта & 8. Дополнительные затраты, связанные со сбытом \\
\hline
\end{tabular}

посредники, молочные заводы и торговые агенты, которые забирают большую часть добавленной стоимости [11]. Совершенствование ценообразования в отрасли является важной частью внутренней государственной политики и регулирования сельскохозяйственных рынков.

В законе о бюджете на 2016 г. на поддержку молочной отрасли было заложено 38,2 млрд руб., что на 9 млрд руб. больше, чем в 2015 г. [6]. Реальный объем субсидии на 1 кг товарного молока в России покрывает в среднем не более 10 \% от закупочной цены сырого молока [11]. Например, в Саратовской области государственную субсидию получают только те хозяйства, которые успевают оформить заявку, а размер государственной помощи в 2015 г. составил около 0,33 евроцента на 1 кг молока, ситуация в 2016-2017 гг. не улучшилась. Очевидно, что данные меры малоэффективны и недостаточны для наращивания объемов собственного производства молока.

При этом в молочной отрасли остаются нерешенными проблемы сокращения поголовья молочного стада и продуктивности животных, низкой производительности труда и роста себестоимости производства, слабой инвестиционной привлекательности и высоких ставок по кредитам. Низкая товарность производимого молока в хозяйствах населения ограничивает доступность сырья для переработки, растет дефицит сырья и зависимость от импорта. Всё это увеличивает долю фальсификата на рынке и замещение молочных жиров продуктами растительного происхождения и т.д. В данных условиях, опираясь на поддержку институтов государственной власти, органов местного самоуправления, муниципалитетов, институтов гражданского общества совместно с бизнес-структурами в подкомплексе, необходимо развитие территориальных агропромышленных кластеров. Это поможет решить, по мнению авторов, проблему совершенствования межотраслевых взаимоотношений и ценообразования.

В Саратовской области целесообразным является создание агропромышленного кластера в молочнопродуктовом подкомплексе АПК, так как существует достаточное количество перерабатывающих предприятий, испытывающих дефицит молока-сырья, что будет стимулировать спрос. Именно молокоперерабатывающие предприятия проявляют интерес к созданию организованной производственно-сбытовой структуры в виде агропромышленного кластера с целью формирования стабильной сырьевой базы вблизи основных перерабатывающих мощностей. К тому же многие сельхозорганизации, рассматривают возможность развития молочного животноводства, но прежде, чем инвестировать средства, они хотят получить гарантии стабильных объемов на рынке сбыта. Для поддержки инициатив в исследовании разработан проект структуры молочно-продуктового кластера, ядро которого будут составлять крупнейшие производители молока (ЗАО Племенной завод «Мелиоратор», ЗАО Племенной завод «Трудовой») и прочие ассоциированные сельскохозяйственные предприятия, действующие молокоперерабатывающие заводы (ОАО «Энгельсский молочный комбинат», ОАО «Саратовский молочный комбинат» и др.), а также предприятия сферы реализации готовой продукции - ООО «Поволжский торговый дом», ООО «Милайн инвест групп», ГУ «УК «Сельхозрынок». Сателлитами кластера будут выступать имеющиеся в регионе информационно-консультационные центры, образовательные и научные учреждения, кредитные организации, поставщики техники и оборудования. Координация будет осуществляться министерством сельского хозяйства и Управляющим центром при министерстве экономического развития Саратовской области.

В исследовании с целью совершенствования ценообразования посредством управления издержками товародвижения была разработана логистическая схема с разбивкой расходов при использовании традиционных каналов товародвижения и каналов в рамках вертикального молочно-продуктового кластера. При работе в кластере сокращаются транспортные расходы, снижаются расходы на поддержание запасов, отгрузкупогрузку и административные издержки по обработке заказов, а общая экономия составит в среднем 44,5 \% в зависимости от варианта структуры затрат на процессы товарообращения. При этом сокращение издержек и исключение дублирования функций дает возможность совершенствовать ценообразование в подкомплексе на разных уровнях.

Заключение. Таким образом, авторами выявлены основные тенденции развития молочно-продуктового подкомплекса РФ, в большинстве случаев, являющиеся результатом разобщенности субъектов рынка и отсутствия эффективной системы перераспределения создаваемой стоимости между субъектами аграрного рынка. Негативно на состояние подотрасли также влияют отсутствие прозрачного механизма создания обоснованной розничной цены на молочные продукты, отстранение государства от процессов регулирования ценообразования, недостаточность государственной поддержки молочного скотоводства и неразвитая инфраструктура в целом.

Эффективной мерой решения проблем развития молочно-продуктового подкомплекса, по нашему мнению, будет создание и функционирование агропромышленного молочного кластера. При этом необходи- 
мо отметить, что в Саратовской области существуют все предпосылки и базовые основания для его создания. В результате проведенных исследований была выявлена эффективность создания такого кластера в регионе, в том числе за счет сокращения издержек и исключения дублирования основных производственных и маркетинговых функций. В рамках кластера, несомненно, появится возможность совершенствовать ценообразование в молочно-продуктовом подкомплексе.

Решая проблемы сельского хозяйства в целом и регулируя процессы ценообразования, государство одновременно будет иметь возможность решения проблем кадровой, кредитной и инвестиционной политики в АПК.

\section{СПИСОК ЛИТЕРАТУРЫ}

1. Итоги 2016 года: производство молока в России снизилось на 0,2 \%. - Режим доступа: http://www. dairynews.ru/news/itogi-2016-goda-proizvodstvo-molokav-rossii-snizi.html.

2. Каткова Е. Россия сливает молоко. Уровень потребления молока в России снижается, производство стагнирует. 08.11.2017. - Режим доступа: https://www.gazeta.ru/ business/2017/11/08/10975766.shtml.

3. Материалы Федеральной службы государственной статистики РФ: официальный сайт. - Режим доступа: http://www.gks.ru.

4. Мировое потребление молока и молочных продуктов растет (2017). - Режим доступа: http://milknet.ru/ news/mirovoe-potreblenie-moloka-i-molochnih-produktovrastet-361437.

5. Минсельхоз рассчитывает на рост производства молока до 39 млн тонн за ближайшие 5 лет. (2016) // Агентство «АгроФакт» - Режим доступа: http://agroconsul. tomsk.ru/news_apk/russia/.

6. Молочная отрасль России - 2017 год // А.С. Белов, А.А. Воронин, М.Э. Жебит. Национальный союз производителей молока, информационно-аналитическое агентство Milknews. - Режим доступа: https://agrovesti. net/lib/industries/dairy-farming/molochnaya-otrasl-rossii2017-god.html.

7. О соотношении денежных доходов населения с величиной прожиточного минимума и численности малоимущего населения в целом по Российской Федерации в I квартале 2017 года. - Режим доступа: http://www.gks.ru/bgd/free/ b04_03/IssWWW.exe/Stg/d02/127.htm.

8. Россия занимает 9 место в мировом рейтинге по производству молока // DairyNews.ru. - Режим доступа: http://www.dairynews.ru/news/rossiya-zanimaet-9-mestov-mirovom-reytinge-po-pro.html.

9. Сердобинцев Д.В., Юркова М.С., Алешина Е.А. Методы выявления и формирования инновационных тер- риториальных кластеров в молочнопродуктовом подкомплексе АПК Поволжья // Молочнохозяйственный вестник. 2017. - № 3 (27). - С. 212-228.

10. Цены на молоко - обзорная статья, подготовленная специалистами Экспертно-аналитического центра агробизнеса «АБ-Центр» www.ab-centre.ru. - Режим доступа: http://ab-centre.ru/page/ceny-na-moloko.

11. Юркова М.С. Особенности процесса ценообразования на продукцию сельского хозяйства в России // Научное обозрение. - 2015. - № 20. - С. 231-235.

12. Юркова М.С., Лиховиова Е.А., Геляжева Д.Н. Проблемы и перспективы современного развития молочного скотоводства // Аграрный научный журнал - 2016. № 8. - C. 95-100.

13. Gerlinda S. Samson, Cornelis Gardebroek, Roel A. Jongeneel (2016). Explaining production expansion decisions of Dutch dairy farmers // NJAS, Wageningen Journal of Life Sciences, Vol. 76, March: P. 87-98. - URL: https://doi. org/10.1016/j.njas.2015.11.007.

14. Jan Alpmann, Vera Bitsch (2017). Dynamics of asymmetric conflict: The case of the German Milk Conflict // Food Policy, No 66: P. 62-72. - URL: http://dx.doi.org/10.2016/j. foodpol.2016.12.002.

15. Mar Maestre, Nigel Poole, Spencer Henson (2017). Assessing food value chain pathways, linkages and impacts for better nutrition of vulnerable groups // Food Policy, No 68: P. 31-39. - URL: http://dx.doi.org/10.1016/j. foodpol.2016.12.007.

16. Susan M. Capalbo, John M. Antle, Clark Seavert (2016). Next generation data systems and knowledge products to support agricultural producers and science-based policy decision making // Agricultural Systems. - URL: http://dx.doi. org/10.1016/j.agsy.2016.10.009.

Лиховцова Елена Александровна, канд. с.-х. наук, доцент кафедры «Экономика АПК», Саратовский государственный аграрный университет имени Н.И. Вавилова. Россия.

Евсюкова Людмила Юрьевна, канд. экон. наук, доцент кафедры «Экономика АПК», Саратовский государственный аграрный университет имени Н.И. Вавилова. Россия.

410012, г. Саратов, Театральная пл., 1.

Тел.: 89379695997.

Юркова Марина Сергеевна, канд. экон. наук, главный научный сотрудник сектора развития сельских территорий, Поволжский научно-исследовательский институт экономики и организации АПК. Россия.

Сердобинцев Дмитрий Валерьевич, канд. экон. наук, главный научный сотрудник сектора развития интеграции и кооперации, Поволжский научно-исследовательский институт экономики и организации АПК. Россия.

410010, г. Саратов, ул. Шехурдина, 12.

Тел.: 89276216274

Ключевые слова: молочно-продуктовый подкомплекс; тенденции; факторы влиянии; кластерное развитии; ценообразование.

\section{MAIN DIRECTIONS OF DEVELOPMENT OF THE REGIONAL MILK AND PRODUCT SUBCOMPLEX}

Likhovtsova Elena Aleksandrovna, Candidate of Agricultural Sciences, Associate Professorof the chair "Economics of AIC", Saratov State Agrarian University named after N.I. Vavilov. Russia.

Evsyukova Lyudmila Yurievna, Candidate of Economic Sciences, Associate Pro-fessorof the chair "Economics of AIC", Saratov State Agrarian University named after N.I. Vavilov. Russia.

Yurkova Marina Sergeevna, Candidate of Economic Sciences, Chief Researcher, Sector of the Rural Territories Development, Volga Research Institute of Econom-ics and Organization of the Agroindustrial Complex. Russia.

Serdobintsev Dmitriy Valerevich, Candidate of Economic Sciences, ChiefRe-searcher, Volga Research Institute of Economics and Organization of the Agroin-dustrial Complex. Russia.
Keywords: milk and product subcomplex; trends; impact factors; cluster develop-ment; pricing.

The trends in the development of the milk and product subcomplex of the Russian Federation and the experience of cluster development in developed countries are analyzed. The possibility of creating a cluster in the Saratov region has been sub-stantiated. This cluster will eliminate duplication of production and selling and marketing functions of the milk market subjects, as well as reduce the total costs by more than $4 \%$ on average. According to the authors, it will lead to an increase in efficiency production and incentives for the development of infrastructure and rural areas. 